\title{
Postoperative Nausea and Vomiting Prophylaxis (PONV) - are we doing too little or too much?
}

Pacheco, J. ${ }^{*}$, Ribeiro M. ${ }^{*}$, Alves, J. *, Vítor, P. *

${ }^{*}$ Anaesthesiology Department, Centro Hospitalar Lisboa Norte EPE

\section{Background}

PONV are associated with decreased patient satisfaction, increased economical costs and delays in discharge. Thus, the identification of patients at risk, effective prophylaxis and treatment are essential. Considering this, we decided to evaluate the incidence of PONV in our centre and ascertain if an appropriate prophylaxis and treatment of PONV were being performed.

\section{Materials and Methods}

Patients admitted to the post anaesthesia care unit (PACU) in the months of July and October of 2017 were included in this prospective study. All the patients were over eighteen years old, and were subject to different types of surgery such as abdominal, urological, orthopaedic and vascular. Data was collected on a designed form filled with information on the preoperative, intraoperative and postoperative periods. For data analysis the Apfel score was used for stratification of the risk of PONV, and the recommendations of the Portuguese Anaesthesiology Society were used in the evaluation of the prophylaxis.

\section{Results and Discussion}

Fifty patients were included in this study, and PONV was diagnosed in $14 \%$ of them, which is similar to the usual incidence mentioned in the literature. The majority of the patients included were subject to an adequate prophylactic scheme (64\%). Evaluating the cases were the prophylactic scheme didn't correlate with their risk of PONV, we concluded that the major tendency was to use more anti-emetics than those deemed necessary by the Apfel score.

Regarding the patients who experienced PONV, we concluded that in $72 \%$ an adequate prophylactic scheme was used. Only in two cases of PONV there was an inadequate prophylaxis, but surprisingly in both of these cases there was an excessive use of anti-emetics. Considering the therapeutic approach, we concluded that the majority of the patients were administred an adequate treatment of PONV.

\section{Conclusion}

The present study evaluated the incidence of PONV in the population admitted to the PACU and the prophylactic therapy administered in the operating room to prevent PONV. We concluded that in some cases, even when an appropriate prophylaxis is administred, PONV still develops. This leads us to think that other factors not included in the Apfel score may carry a significant impact in the development of PONV.

\begin{tabular}{|c|c|}
\hline \multicolumn{2}{|c|}{ Population - descriptive analysis } \\
\hline Gender & $60 \%$ Female, $40 \%$ male \\
\hline Smoking habits & $\begin{array}{r}80 \% \text { nonsmokers, } 20 \% \\
\text { smokers }\end{array}$ \\
\hline $\begin{array}{r}\text { History of PONV or Motion } \\
\text { Sickness }\end{array}$ & $12 \%$ \\
\hline Postoperative Opioids & $20 \%$ \\
\hline
\end{tabular}

\begin{tabular}{|r|r|r|r|}
\hline \multicolumn{2}{|c|}{$\begin{array}{c}\text { Population Distribution } \\
\text { considering Risk Factors to } \\
\text { PONV }\end{array}$} & \multicolumn{2}{|c|}{ Inicidence of PONV } \\
\cline { 3 - 4 } & $\begin{array}{c}\text { Predicted by } \\
\text { Apfel Score }\end{array}$ & Observed \\
\hline $0-1$ & $44 \%(\mathrm{n}=22)$ & $10-20 \%$ & $9 \%$ \\
\hline 2 & $44 \%(\mathrm{n}=22)$ & $30-40 \%$ & $22 \%$ \\
\hline $3-4$ & $12 \%(\mathrm{n}=6)$ & $50-80 \%$ & $0 \%$ \\
\hline
\end{tabular}
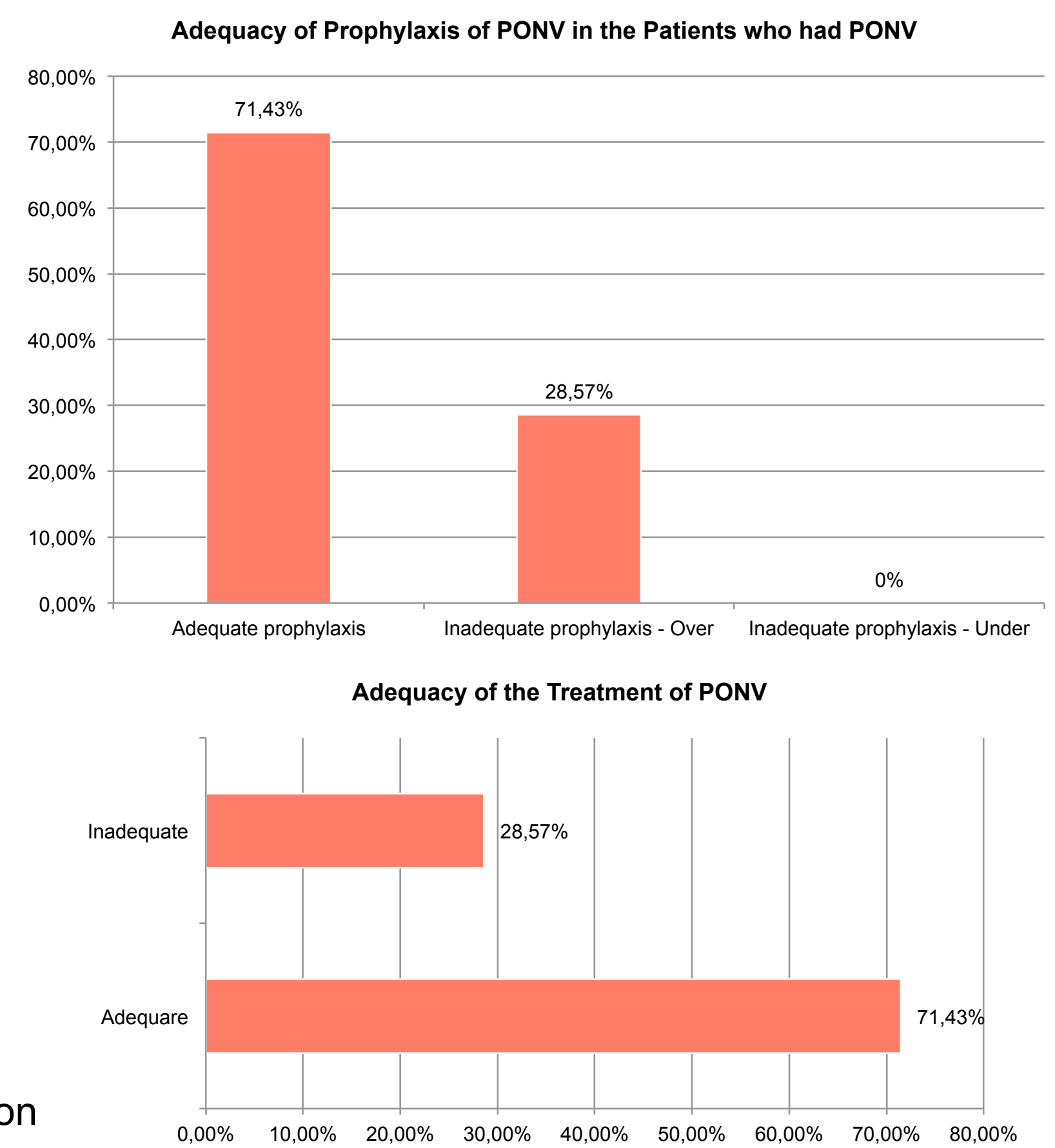

References

1. Gan TJ, Meyer T, Apfel CC et al. - Consensus guidelines for managing postoperative nausea and vomiting. Anesth Analg 2003;97:62-71

2. Vieira V. et al. Recomendações portuguesas para a profilaxia e tratamento das náuseas e vómitos no pós-operatório em cirurgia de ambulatório. Revista Sociedade Portuguesa de Anestesiologia. 